\title{
Professores e lacunas formativas em avaliação da aprendizagem: evidências e problematizações $^{1}$
}

\author{
Valéria Aparecida de Souza Siqueira² \\ ORCID: 0000-0003-2222-9677 \\ Pâmela Félix Freitas ${ }^{2}$ \\ ORCID: 0000-0003-2219-2173 \\ Ocimar Munhoz Alavarse ${ }^{2}$ \\ ORCID: 0000-0002-8102-1668
}

\section{Resumo}

0 presente artigo problematiza a formação docente em avaliação da aprendizagem partindo de evidências de que são raros os cursos de licenciatura que oferecem formação técnica e teórica nesse tópico, levando à reprodução de modelos aos quais o professor fora exposto enquanto aluno e das escolas onde passa a trabalhar sem a necessária crítica, reverberando em procedimentos, instrumentos e critérios de avaliação da aprendizagem sem validade e fidedignidade, com forte impacto sobre a trajetória escolar dos alunos e que não permitem o uso dos resultados para organizar o processo de ensino e aprendizagem. 0 trabalho foi ancorado em pesquisa bibliográfica, observações de oito Conselhos de Classe em uma escola da Rede Municipal de Ensino de São Paulo e respostas de 1.083 professores a um questionário aplicado no âmbito de uma formação continuada em avaliação na mesma rede. Das observações realizadas, verificamos que as apreciações do professor, para efeitos de aprovação e reprovação, se apoiam em fontes não cognitivas como, por exemplo, comportamento e participação. Ao mesmo tempo, as lacunas de conhecimento demonstradas nas respostas aos questionários evidenciam uma formação docente em avaliação frágil e, em muitos casos, ausente, com equívocos que incidem diretamente na prática avaliativa, desde o emprego de procedimentos e instrumentos inadequados à adoção de critérios flutuantes com imprecisões que comprometem todo o processo de avaliação, com prejuízos aos alunos. 0 trabalho mostra a urgência de retomarmos o debate acerca das práticas avaliativas realizadas na escola, atualmente eclipsadas pela centralidade das avaliações externas no cenário educacional brasileiro.

\section{Palavras-chave}

Formação docente - Avaliação da aprendizagem - Ensino e aprendizagem.

1- Todo o conjunto de dados que dá suporte aos resultados deste estudo foi publicado no próprio artigo.

2- Universidade de São Paulo, São Paulo, SP, Brasil. Contatos: valeriasiqueiral8@gmail.com; pamelafelixfreitas@gmail.com; ocimar@usp.br

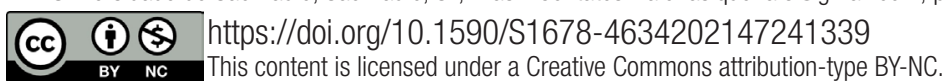




\section{Teachers and teacher education gaps in learning evaluation: evidence and questions}

\section{Abstract}

The present article problematizes teacher education in learning evaluation based on evidence that licensure programs that provide technical and theoretical training on this topic are rare, which leads to the reproduction of models the teacher had been exposed to as a student and of the schools he starts to teach at without the necessary criticism, thus resulting in learning evaluation procedures, instruments and criteria with no validity or reliability, with a heavy impact on students' educational trajectory and which do not allow using the results to organize the teaching and learning process. The work is founded on bibliographic research, observations of eight Class Councils at a school in the Municipal Education System of São Paulo and answers of 1,083 teachers to a questionnaire administered in a continuing education course on evaluation in the same education system. From the observations, we found that the teacher's appreciation on whether the student should be retained or advance to the next grade are based on non-cognitive sources such as behavior and participation. In addition, the knowledge gaps demonstrated in the answers to the questionnaires show poor or, in many cases, no training related to evaluation, with mistakes that directly affect the evaluation practice, from the use of unsuitable procedures and instruments to the adoption of varying, imprecise criteria that compromise the whole evaluation process, to the detriment of students. The work shows we should urgently resume the debate on the evaluation practices carried out in schools, which is currently eclipsed by the centrality of external evaluations in the Brazilian educational arena.

\section{Keywords}

Teacher education - Learning evaluation - Teaching and learning

\section{Introdução}

A avaliação educacional como uma prática marcante do cotidiano escolar é uma atividade comum da docência. 0 professor tanto avalia periodicamente seus alunos quanto é convidado a, cada vez mais, interagir com iniciativas promovidas por instituições externas, como agências governamentais ou mesmo organizações internacionais. A dimensão de avaliador, portanto, faz parte das atribuições dos professores prevista tanto na legislação educacional como expressa em editais de concursos públicos para o posto. A competência avaliadora faz parte, também, do núcleo duro de Referenciais Profissionais Docentes de vários países, como é o caso de províncias canadenses, como Ontário e Quebec, Estados Unidos da América do Norte (EUA), Inglaterra, Alemanha, Argentina, Austrália, Chile, Cingapura, Colômbia, Equador, Escócia, Finlândia, Líbano, México, Peru, Polônia, Portugal, Nova Zelândia, dentre outros países. Tais documentos definem os 
conhecimentos e habilidades que são próprios à atividade docente e delineiam o que se espera que o professor saiba e faça.

Todavia, identificamos, na literatura especializada sobre o tema, evidências de que este tema ainda é pouco tratado nos cursos de licenciatura (GATTI et al., 2010; ROJAS, 2007; SILVA et al., 2016; VILLAS BOAS; SOARES, 2016). Entretanto, a formação de professores deveria incorporar, segundo Tardif (2013), um repertório de saberes baseados no conhecimento profissional efetivamente utilizado no seu cotidiano de trabalho. Entendemos que essa lacuna formativa configura o que Alavarse (2013) chama de "paradoxo docente", pois ao mesmo tempo que se exige uma formação que garanta contato prévio com tarefas da profissão, a avaliação praticamente não tem lugar.

0 presente artigo visa, portanto, problematizar a formação docente relativa à avaliação partindo da constatação de que o professor raramente recebe formação técnica e teórica para avaliar seus alunos, levando-o a reproduzir modelos de avaliação a que fora exposto enquanto aluno, reverberando em procedimentos e instrumentos de avaliação improvisados com forte impacto sobre a trajetória escolar dos alunos. Espera-se refletir sobre os efeitos que uma prática avaliativa frágil em conceitos e técnicas pode acarretar sobre o futuro educacional dos estudantes, incidindo sobre seu futuro acadêmico, favorecendo e até mesmo ampliando as desigualdades sociais, transformando-as em desigualdades escolares, impossibilitando um tratamento equitativo à luz do que asseveram Dubet (2008) e Crahay (2002).

0 trabalho foi ancorado, além da pesquisa bibliográfica, por observações de Conselhos de Classe e respostas de professores a questionário aplicado em uma formação continuada em avaliação educacional. Os dados aqui apresentados integram pesquisas mais amplas de doutorado (FREITAS, 2019; SIQUEIRA, 2017) e foram adquiridos por meio de registros de observação de oito Conselhos de Classe de turmas do ensino fundamental dos anos iniciais e dos anos finais em uma Escola Municipal de Ensino Fundamental (EMEF) da Rede Municipal de Ensino de São Paulo (RME-SP), entre os anos de 2014 e 2016, e de respostas a questionários aplicados a uma amostra de 1.083 professores que participaram de uma Formação em Avaliação Educacional, promovida pela Secretaria Municipal de Educação de São Paulo (SME-SP), entre os anos de 2015 e 2016. Ainda que os resultados não sejam generalizáveis, as informações que eles expressam podem indicar hipóteses mais amplas e, sobretudo, adensar as problematizações aqui pretendidas.

Compreendemos que a avaliação educacional representa um importante elemento da prática docente, constituindo-se em ferramenta indissociável do acompanhamento da aprendizagem dos alunos, com efeito direto sobre seu percurso escolar. Sua concretização se reflete sobre a qualidade da educação e de sua efetivação definem-se percursos escolares com forte influência, inclusive, sobre a permanência ou a evasão escolar do aluno, como revela Bowers (2019) em relação a marcas que a avaliação deixa nos estudantes e que incidem, inclusive, na definição pela continuidade ou não dos estudos, especialmente no ensino médio. Bowers (2019) afirma que o juízo do professor é o que, de fato, acompanha o aluno em sua história escolar, haja vista que o fluxo escolar é definido, via de regra, pelas apreciações que o professor realiza sobre as produções de seus alunos, que se expressam, por sua vez, em notas ou conceitos a partir do que se decidem aprovações e reprovações. 


\section{Equidade e avaliação educacional}

0 debate acerca da avaliação educacional, embora não seja recente, mantém-se relevante e atual, uma vez que a democratização do ensino não garantiu o acesso à "igualdade de conhecimentos adquiridos", como salienta Crahay (1996, 2002, 2009). À ascensão escolar de amplos contingentes da população historicamente alijados seguiu-se a necessidade de adaptação das escolas à diferença e, consequentemente, o seu atendimento fundado na perspectiva de uma escola inclusiva.

0 ato de avaliar tarefas realizadas cotidianamente pelos estudantes é um traço marcante do ofício docente e, como tal, tem impacto sobre a efetivação de um atendimento educacional de qualidade, que é um direito previsto na Constituição Federal (BRASIL, 1988), reiterado no Estatuto da Criança e do Adolescente (ECA, 1990), garantido na Lei de Diretrizes e Bases da Educação Nacional (LDB, 1996) e referendado nos principais documentos oficiais curriculares, como nas Diretrizes Curriculares Nacionais da Educação Básica (DCNEB, 2013) e, mais recentemente, pela Base Nacional Comum Curricular (BNCC, 2017). Nota-se que a concepção de qualidade pautada na igualdade de condições de acesso e permanência norteou os documentos oficiais da área educacional durante a década de 1990 e início dos anos 2000, sendo que a Declaração Mundial de Educação para Todos, de 1990, a assinalara anteriormente entre seus objetivos e indicava a necessidade de se "universalizar o acesso à educação e promover a equidade" (CONFERÊNCIA..., 1990).

Percebe-se que o discurso oficial produzido nos últimos trinta anos priorizou o atendimento às diferenças, com ênfase nos princípios de igualdade e equidade. Ao mesmo tempo, há uma expressiva produção acadêmica no Brasil que até o final dos anos 1980 e início dos anos 1990 denuncia a prática de avaliação dos professores como instrumento de seleção e exclusão (HOFFMANN, 1991, 1993; LUCKESI, 1992, 2006; PATTO, 1990; SOUSA, 1991; SOUSA, 1986, 1994), mas que curiosamente cede espaço para discussões a respeito das avaliações externas que, no decorrer das décadas de 1990 e 2000, ocupam centralidade no debate acerca da qualidade da educação (AFONSO, 1998; ARELARO, 2003; CASTRO, 2000, 2007, 2009; DÍAZ BARRIGA, 2008; ESTEBAN, 2014; FREITAS, 2011; GATTI, 2011; SOUSA; OLIVEIRA, 2010).

Assim, chama a atenção que, apesar dos desafios da avaliação da aprendizagem interna largamente expostos pela literatura até o final dos anos 1980, esta tenha cedido espaço para as avaliações externas ao longo das décadas de 1990 e 2000. Entretanto, pesquisas recentes (FREIRE, 2017; SIQUEIRA, 2017) mostram que este não é um assunto encerrado, mas antes, necessita ser recuperado e reinserido no debate educacional a partir de achados que revelam, no cotidiano escolar de escolas públicas de Ensino Fundamental, rara formação em avaliação educacional e concepções de avaliação que não atendem ao princípio de equidade, mas, sim, acabam por reforçar um projeto pedagógico excludente em alguns momentos, assistencialista em outros, direcionado por posturas de conveniência, dependentes da situação em questão.

Permeado por contradições, o espaço escolar é um terreno de disputas onde se observou por muito tempo a valorização do mérito objetivado no esforço, na participação e no comportamento dos alunos em sala de aula. Apesar da inserção do discurso sobre 
a igualdade e, mais recentemente, a equidade, Dubet (2008) denuncia que as classes populares ascenderam à escola, mas têm ignoradas a desigualdade social e de entrada que as caracterizam, prevalecendo um sistema meritocrático no qual repousa a igualdade de oportunidades.

A esse respeito, Crahay (2013) adverte que a escola, uma vez inserida em um contexto social, traz implícito um perfil desejável de aluno que se adapte às estruturas e modos de funcionamento dessa sociedade, praticando, assim, um modelo de justiça de acordo com os princípios em que se apoia, que pode ser uma justiça meritocrática, uma justiça igualitária ou uma justiça corretiva. Entende-se por justiça meritocrática ou o "justo reconhecimento dos méritos" (CRAHAY, 2002, p. 53) aquela que está baseada na igualdade de oportunidades que desconsidera as desigualdades de partida e enfatiza a ideologia do dom. A justiça igualitária, por sua vez, se efetiva por meio da igualdade de tratamento e, ainda que se mostre satisfatória em um primeiro instante, acaba por se revelar incipiente, uma vez que oferecer o mesmo tratamento a todos não representa melhores condições de aprendizagem. A justiça corretiva, em contrapartida, se mostra adequada para atendimento aos desfavorecidos, pois está apoiada na igualdade de resultados a qual apregoa um tratamento equitativo. Para Crahay (2013), somente a justiça corretiva é capaz de superar o modelo meritocrático que sustenta a escola.

Qualquer que seja o conceito de justiça em que esteja calcada a escola, a avaliação estará a serviço de sua efetivação, seja excluindo aqueles que, porventura, não se enquadram no perfil definido pela meritocracia, seja por meio da identificação dos conhecimentos com vistas à elaboração de práticas posteriores que possam contribuir para a aprendizagem de cada um.

Dos documentos que organizam a educação básica na história recente do Brasil, depreende-se um alinhamento com as ideias supracitadas de Crahay e Dubet, com maior atenção aos alunos de extratos socioeconômicos inferiores, o que impõe à avaliação o desafıo de discriminar positivamente os alunos, identificando suas proficiências para desenvolver situações didáticas que favoreçam o nível de aprendizagem em que cada um se encontra, vislumbrando objetivamente a igualdade de conhecimentos adquiridos ao final do processo de ensino e aprendizagem.

\section{Lacunas formativas e critérios de avaliação flutuantes}

Apesar de toda importância atribuída à avaliação, ainda que esta seja uma atividade inerente à prática profissional do professor, constata-se o paradoxo referido por Alavarse (2013), pois a formação inicial, cujas bases orientam o ingresso à docência, mostrase insuficiente e até isenta de conhecimentos quanto aos fundamentos conceituais, procedimentais e técnicos da prática avaliativa.

Além do fato de que a avaliação determina trajetórias escolares por meio de aprovação e reprovação, há que se considerar que a prática avaliativa é um ato social cujos impactos se fazem sentir na vida do estudante, influenciando, inclusive, sua decisão sobre a permanência ou não no ambiente escolar, como mostra o estudo de Bowers (2019), que revelou forte relação entre as notas atribuídas por professores e a permanência ou evasão de estudantes. 
A pesquisa reafirma o que muitos trabalhos já revelaram sobre essa prática, que ela se apoia em evidências cognitivas (conhecimento acadêmico ou proficiência) e não cognitivas (comprometimento, esforço, atenção, participação, engajamento, persistência, realização de atividades etc.) (Cf. BROOKHART, 1994; CISEK; FITZGERALD; RACHOR, 1995) para atribuição de notas. Para Feldman (2019, p.1), "quando os professores combinam habilidades sociais, comportamento e esforço em um único conceito ou nota, é impossível discernir os pontos fortes e fracos do aluno em cada um desses aspectos, tornando a expressão desse resultado vago, confuso e até inválido". 0 produto dessa avaliação é uma miscelânea de informações que pode mascarar a proficiência propriamente dita e comprometer os encaminhamentos que potencialmente seriam dados aos resultados. As notas atribuídas aos alunos fornecem, portanto, informações imprecisas e enganosas (misleading) sobre o que eles de fato sabem, conclui o autor. A atribuição de notas de professores pode, ainda, variar dentro de uma mesma escola, conforme a compreensão que os professores têm sobre o desempenho (acadêmico ou não) do aluno. Brookhart et al. (2016) detectaram padrões diversos no modo de avaliar entre redes, escolas e professores, atribuídos: (i) à diferença ou à falta de critérios de classificação, (ii) à severidade ou à clemência do professor-avaliador, (iii) à qualidade dos trabalhos realizados pelos alunos, (iv) à escala de proficiência utilizada pelo docente, e (v) até mesmo a erro do professor. Também é possível encontrar na literatura diferenças entre o julgamento do professor expresso em notas e conceitos e o desempenho de alunos em avaliações de aprendizagem externas, como revelaram Alavarse, Machado e Leme (2013, p. 11), que cotejaram resultados da Prova São Paulo ${ }^{3}$ e de avaliações realizadas pelos professores,

[...] em uma classe de $2^{\circ}$ ano com, aproximadamente, 40 alunos, em Língua Portuguesa, encontramos dois alunos que obtiveram conceito NS (não suficiente) nas avaliações internas e foram reprovados, embora tenham ficado nos níveis adequado e avançado na Prova São Paulo. Por outro lado, encontramos um aluno que embora tenha ficado com conceito S (Suficiente) na avaliação dos professores não conseguiu ultrapassar o nível básico na Prova São Paulo. Nessa mesma turma, porém na disciplina de Matemática, a incongruência permanece. Três alunos foram considerados reprovados pelos professores, embora tenham ficado entre os níveis adequado e avançado na Prova São Paulo e, seis alunos que obtiveram conceito S (Suficiente) dos professores figuraram entre aqueles com resultado abaixo do básico na Prova São Paulo.

A desigualdade de tratamento pode, assim, se manifestar nas práticas avaliativas, impactar a trajetória escolar de alunos (Cf. CORTESE, 2006; CRAHAY, 2002) e sofrer vieses implícitos de preconceitos raciais, de classe social e/ou de gênero, segundo Feldman (2019).

Nos tópicos seguintes, problematizaremos a avaliação desenvolvida pelos professores com base em dados coletados por meio de questionários e dos registros das observações de reuniões de Conselhos de Classe.

3- A Prova São Paulo classificava os alunos, a partir da proficiência atingida em provas padronizadas, em quatro níveis: abaixo do básico, básico, adequado e avançado. As provas internas dos professores atribuem conceitos que podem ser: NS (não suficiente), S (suficiente) e P (plenamente suficiente), sendo que os alunos que obtêm NS são reprovados (ALAVARSE; MACHADO; LEME, 2013). Foi uma iniciativa da SME durante o período de 2007-2012, suspensa de 2013 a 2017 e retomada em 2017. 


\section{Análise dos questionários}

Em nossa pesquisa, detectamos uma forte subjetividade na avaliação dos professores que apontam a participação dos alunos nas aulas como o critério ${ }^{4}$ de avaliação mais utilizado, com 65,4\%, como ilustra o Gráfico 1.

Gráfico 1 - Critérios de avaliação*

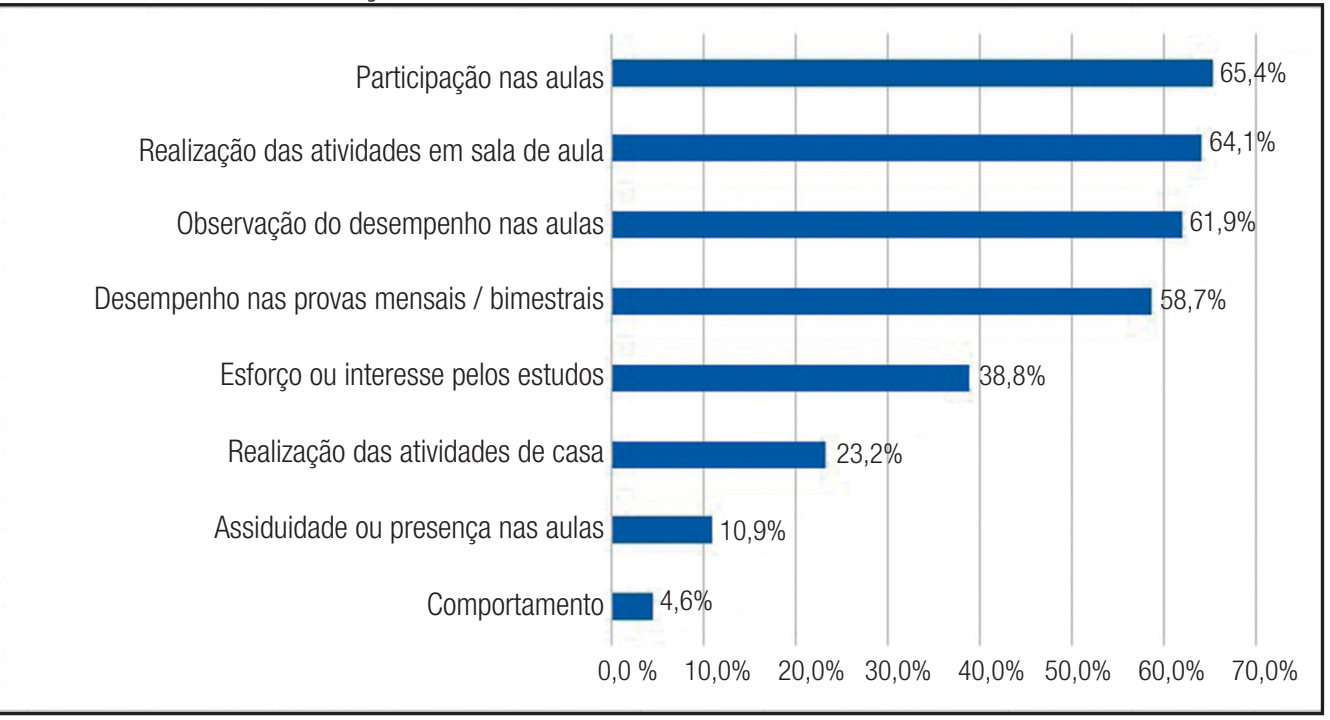

Fonte: Freitas (2019, p. 80).

* Este item do questionário admitia que o respondente assinalasse mais de uma alternativa.

Contudo, a observação indicada em terceiro lugar como um critério de avaliação, além de um aspecto subjetivo, seria considerada um instrumento de avaliação e não critério. Além de um entrave conceitual, o fato de 61,9\% dos professores terem mencionado esse aspecto pode ser problematizado: o que estaria sendo objeto dessa observação?

Também foram apontados como critérios, mas em menor escala, o esforço ou interesse dos alunos pelos estudos $(38,8 \%)$, a assiduidade ou presença nas aulas $(10,9 \%)$ e o comportamento em sala (4,6\%). A frequência de critérios subjetivos nas respostas dos professores realça fragilidades na prática avaliativa que precisam ser destacadas, dadas as potenciais implicações do julgamento do professor na trajetória escolar dos alunos. Por outro lado, compondo critérios de avaliação mais objetivos, 64,1\% dos professores afırmaram considerar a realização das atividades propostas em sala de aula, resposta que ficou na segunda posição. A verificação do desempenho dos alunos nas provas mensais/bimestrais ocupou o quarto lugar nas indicações dos docentes, com 58,7\%. Já o cumprimento das atividades para casa foi o sexto critério de avaliação mais mobilizado pelos professores, com $23,2 \%$ das respostas.

4- Embora, a rigor, a participação dos alunos nas aulas, por exemplo, não seja um critério de avaliação da aprendizagem e sim um objeto de avaliação, mantivemos o questionamento sobre esse e outros aspectos, tais como esforço, assiduidade e comportamento, devido a sua presença na fala dos professores e na composição das notas, como destaca a literatura. Não há uma avaliação formal desses aspectos, mas mesmo assim é uma marca nos processos de avaliação conduzidos pelos docentes. 
A escolha do comportamento e da participação dos alunos como objetos de avaliação evidenciam a dificuldade que os professores têm nessa prática, pois, embora sejam relevantes para a aquisição de aprendizagens, esses aspectos não seriam objetos prioritários de avaliação, desviando o foco da aprendizagem de conteúdos, objetivo central das atividades de ensino. Adicionalmente, a avaliação desses quesitos de acentuado caráter subjetivo costuma ser realizada sem a devida precisão por meio de procedimentos de observação, não havendo rigor e registro. A preocupação com aspectos comportamentais denota também o caráter de controle de que ainda se reveste a avaliação e levanta a suspeita de que alunos mais tímidos ou mais irrequietos, por exemplo, possam ser prejudicados quando se privilegiam os critérios "participação" e "comportamento".

Por toda a complexidade que permeia o campo das práticas avaliativas e suas reverberações sobre a trajetória de vida do aluno, avaliado continuamente ao longo de pelo menos catorze anos de escolarização obrigatória, seria de se esperar que a dimensão da avaliação recebesse especial atenção nos cursos de formação inicial de professores. Entretanto, os dados levantados pelos questionários reafırmam a realidade alarmante apontada pela literatura, revelando que menos de 1\% dos cursos de formação inicial docente apresenta conteúdo formal em avaliação (Cf. GATTI et al., 2010), o que levanta alguns questionamentos, entre eles, como os professores aprendem a avaliar se os cursos preparatórios não abordam a avaliação ou o fazem de maneira superficial? E ainda, sem uma formação inicial que os prepare para a prática avaliativa, como os professores avaliam seus alunos? Quais são as bases em que se apoiam, quais são as fontes que alimentam seu saber-fazer? E, finalmente, quais seriam os impactos de uma avaliação realizada por professores desprovida de conhecimentos teóricos e técnicos?

Corroborando a lacuna formativa em avaliação, evidenciada pela literatura, os dados de nossa pesquisa desnudam um resultado alarmante: 85,1\% ( $\mathrm{N}=922)$ dos professores aprenderam a avaliar no cotidiano escolar. Essa constatação sugere um nível de amadorismo ou improviso desprovido de bases teóricas no desenvolvimento dessa prática que merece ser investigado. 0 Gráfico 2 apresenta o mapeamento das formas pelas quais os professores desenvolvem esse saber.

Gráfico 2 - Como os professores aprendem a avaliar ${ }^{\star}$

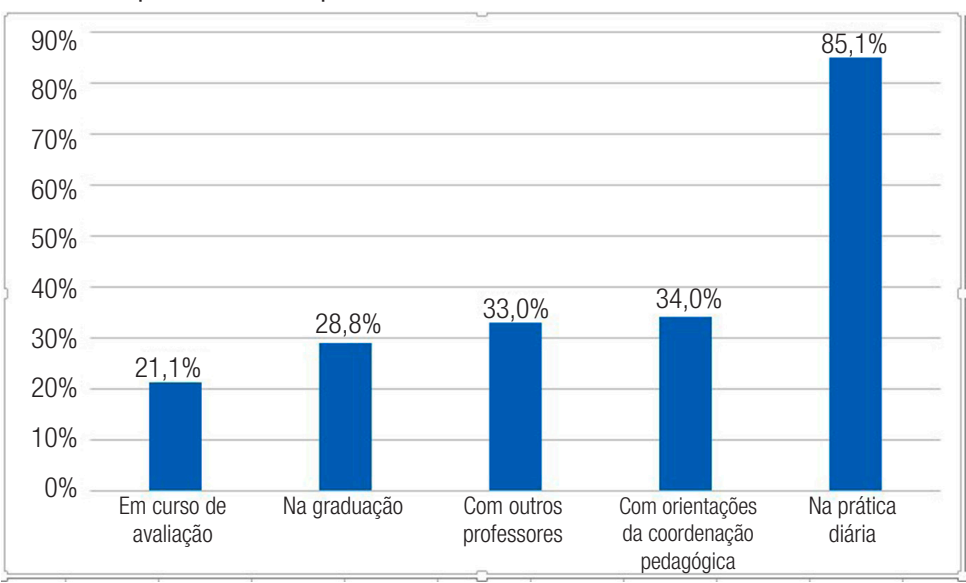

Fonte: Freitas (2019, p. 80).

* Este item do questionário admitia que o respondente assinalasse mais de uma alternativa. 
Para 34\% dos professores, a expertise de avaliar foi adquirida com o apoio de orientações da Coordenação Pedagógica, o que coloca nas mãos desses profissionais uma tarefa para a qual eles mesmos também não tiveram formação específica. Outra parcela de docentes, 33\%, desenvolveu bases para a prática avaliativa junto aos pares mais experientes, que, provavelmente, também carregam as mesmas fragilidades formativas.

A esse respeito, Tardif (2013, p. 561) enfatiza que "o antigo saber de experiência sobre o qual se fundava a formação em escolas normais deve dar lugar ao conhecimento especializado, baseado na pesquisa universitária”. Assim, o savoir-évaluer, como prática inerente ao trabalho do professor, deveria receber uma notável instrução nos cursos preparatórios.

0 Gráfico 2 também revela que apenas 28,8\% dos respondentes declararam ter estudado avaliação educacional no nível da graduação e 21,1\% em cursos de avaliação, reforçando a urgência da presença dessa matéria em processos de formação tanto inicial como continuada. Contudo, não há evidências sobre quais são os indicativos de qualidade para essa formação, qual a carga horária ideal a ser dedicada a esses cursos, se devem ser cursos presenciais ou a distância, se deveriam ser obrigatórios ou optativos e, principalmente, quais são os conteúdos adequados e de que modo eles serão trabalhados.

A constatação de que os professores aprendem a avaliar por meios menos formalizados, sem negar a importância desse tipo de aprendizado, sublinha a preocupação com o fato de que tais expedientes não permitem a adoção de processos avaliativos mais consistentes.

\section{Análise dos Conselhos de Classe}

Considerando a importância da avaliação educacional para a igualdade de conhecimentos adquiridos e a constatação de insuficiente formação em avaliação a que têm acesso profissionais docentes, também recorremos à instância dos Conselhos de Classe para apreendermos quais concepções balizam sua prática e a efetivação de seus julgamentos para atividades de seus alunos e, consequentemente, a consolidação destes na aprovação ou reprovação dos estudantes.

Analisando documentos do Programa Mais Educação São Paulo, política em vigor à época da coleta de dados, percebemos que grande destaque era conferido à avaliação, descrita como "o momento em que a sala de aula e o trabalho dos alunos e dos professores se vestem de gala” (SÃO PAULO, 2014b, p. 9). Regulamentado pela Portaria 5.930/20135', $\mathrm{o}$ art. 15 do referido programa define que

$\S 8^{\circ}$ - Ao final de cada bimestre deverão ser previstas reuniões de Conselho de Classe visando assegurar o acompanhamento sistemático dos avanços e dificuldades do processo de ensino e de aprendizagem.

Em outro documento, Portaria 5.941/20136, os artigos 52 e 53 são dedicados aos Conselhos de Classe. De acordo com o documento,

\footnotetext{
5 - Portaria 5.930/2013 - Regulamenta o Decreto n. 54.452, de 10/10/2013, que institui o Programa de Reorganização Curricular e Administrativa, Ampliação e Fortalecimento da Rede Municipal de Ensino de São - "Mais Educação São Paulo".

6- Portaria 5.941/2013 - Estabelece normas complementares ao Decreto n. 54.454, de 10/10/2013, que dispõe sobre diretrizes para a elaboração do Regimento Educacional das Unidades da Rede Municipal de Ensino e dá outras providências.
} 
Art. 52 - As Reuniões de Conselho de Classe são momentos de tomada de decisão coletiva quanto ao processo contínuo de avaliação, recuperação, compensação de ausências e promoção dos educandos, quando for o caso, de acordo com o Projeto Político-Pedagógico e os princípios estabelecidos nas diretrizes do Regimento Educacional.

Art. 53 - 0 Conselho de Classe será composto pela Equipe Gestora e Docente da Unidade Educacional podendo ser ampliado de acordo com o Projeto Político-Pedagógico e reunir-se-á bimestralmente, observadas as diretrizes estabelecidas em Portaria específica.

0 Programa orienta que participação nas aulas pode ser uma forma de avaliar "considerando a especificidade e personalidade de cada aluno" (SÃO PAULO, 2014b, p. 16). Sobre a participação, o documento pondera sobre a necessidade de se estabelecerem critérios para essa observação,

Faz-se necessário questionar o que está realmente sendo avaliado: o rendimento está sendo considerado como satisfatório ou insatisfatório em função do quê? É importante observar e considerar nos critérios de avaliação as oportunidades oferecidas. (SÃO PAULO, 2014b, p. 15).

Nesse sentido, "ao mesmo tempo em que o acesso à escola contribui para diminuir as desigualdades sociais, os efeitos dessas desigualdades influem fortemente nos resultados escolares" (SÃO PAULO, 2014a, p. 32). Assim, o documento alerta para o risco de que a interação entre a unidade escolar e a realidade social acabe por ampliar as desigualdades fruto da estrutura social e adverte que "apenas a qualificação e a relação com a equipe impactam a equidade quanto a cor/raça do aluno” (SÃO PAULO, 2014a, p. 34). Nesse quadro, o Programa Mais Educação São Paulo invoca a qualidade social como objetivo para se alcançar uma educação de qualidade e elenca alguns princípios, entre eles:

- Qualidade social como acesso ao conhecimento, não como acesso ao consumo;

- A ampliação do acesso e atendimento a toda a população não se antagoniza à produção pedagógica de serviços de qualidade;

- Centralidade do educando e sua aprendizagem, sejam crianças, jovens ou adultos;

- Compromisso das equipes gestora e docente com a aprendizagem dos educandos. (SÃO PAULO, 2014a, p. 21).

A análise dos documentos oficiais nos permite inferir uma concepção de atendimento escolar equitativo com ênfase em um processo de avaliação formativo e processual que tem na instância Conselhos de Classe o local privilegiado para acompanhamento dos alunos, para reflexão e reorientação de práticas pedagógicas. Para Dalben (1996), a função dos Conselhos é orientar os professores na avaliação permanente dos alunos, a fim de analisar as causas de rendimentos altos e baixos e de criar condições de assistência aos que apresentam dificuldades de aprendizagem.

Por outro lado, Mattos (2005) chama a atenção para o fato de que nessa instância os professores tendem a manifestar suas concepções mais livremente, o que possibilita uma visão mais ampla do projeto pedagógico, desvelando processos mais intrínsecos da escola. 
Assim, ao analisarmos os Conselhos de Classe, procuramos identificar de que forma os professores expressam seu julgamento acerca das produções de seus alunos, que descrição pedagógica fazem para fins de acompanhamento de seus alunos. Airasian e Abrams (2003) revelam que, antes de avaliarem o desempenho dos alunos em suas tarefas cognitivas diárias, há uma espécie de aprendizagem prévia dos estudantes, com o uso de várias fontes de informação para que o professor aprenda sobre seus alunos. Essas fontes são multirreferenciais e podem incluir comentários de professores anteriores, comentários na sala dos professores, registros escolares oficiais, desempenho de irmãos anteriores, observações formais e informais em sala de aula, registros de atitude com pontuações e até mesmo conversas com os próprios alunos. Esse conjunto de percepções e expectativas que os professores formam a respeito de seus alunos influenciam a maneira como eles estabelecem regras, planejam instrução, interagem com os estudantes, interpretam e julgam o desempenho do aluno.

Nos Conselhos assistidos, os professores expressaram suas convicções sobre avaliação mais abertamente, revelando as relações desta com o quadro mais amplo de suas concepções sobre ensino e aprendizagem, desvelando processos mais intrínsecos da escola. Notamos que, ao emitir juízos para aprovação ou reprovação, os professores tinham dificuldades para delimitar o objeto de avaliação, privilegiando comportamento e participação em detrimento da aprendizagem. A esse respeito, Brookhart (2017) pondera que a atribuição de notas deve ser baseada em dados de desempenho apenas, o que não significa que o professor deva ignorar o restante de informações que obtém a respeito dos alunos como comportamento, participação e empenho. Mas essas informações são relevantes para conhecimento do professor sobre seus alunos de modo que este organize situações de maior interação nas quais possa conversar com seus alunos, inspirando-os.

Feldmann (2019) reafirma esse quadro e mostra que professores classificam seus alunos intuitivamente, e não fundamentados por uma formação específica, resultando em práticas tradicionais de classificação com atribuição de notas que fornecem informações pouco claras e muitas vezes enganosas para pais, estudantes e escola.

Considerando os equívocos dos professores como lacunas formativas em avaliação com consequente fortalecimento de concepções que determinam práticas docentes (Cf. BROWN, 2004, 2008; PAJARES, 1992; THOMPSON, 1992), vimos nas reuniões de Conselhos de Classe os efeitos perversos desse quadro de rara formação sobre a vida escolar dos alunos interferindo em percursos escolares de formas variadas.

Identificamos, por exemplo, que nos anos iniciais do ensino fundamental, os professores, sobretudo nas etapas escolares em que não havia a possibilidade de reprovação, centravam sua apreciação em questões pedagógicas, não isentas de polêmicas, mas focadas no progresso dos alunos, em seus avanços, dificuldades e desafios. Nessas ocasiões, refletiam sobre estratégias para evitar a reprovação ao final dos ciclos com preocupações voltadas à aprendizagem. Entretanto, nos Conselhos, ainda nos anos iniciais, em que havia possibilidade de retenção, a crença nos benefícios da reprovação se destacou. Em um deles, de $5^{\circ}$ ano, a professora alega que a falta de acompanhamento da família é o que dificulta o desenvolvimento de um de seus alunos e recomenda: 
[É] melhor reprovar. [0] menino é perdido. Tem 66 faltas e o avô veio bêbado, é melhor reprovar e colocar no $2^{\circ}$ ano e ter acompanhamento do $5^{\circ}$, pois ele não consegue fazer o ba-be-bi-bo-bu. (Professora Melissa ${ }^{7}$, E. F. anos iniciais).

Em outro Conselho, desta vez no $3^{\circ}$ ano do ensino fundamental, fatores não cognitivos prevalecem na apreciação da professora, que assim se justifica para reprovar o aluno:

[...] é silábico sem valor, ele não tem problemas de aprendizagem, no entanto, não tem vontade de aprender. [...] é melhor reter, porque no $4^{\circ}$ ano tem muita leitura e ele não vai conseguir acompanhar. (Professora Genoveva, E. F. anos iniciais).

Em muitos Conselhos de Classe verificamos critérios e objetos de avaliação flutuantes, comportamento e participação dos alunos como objetos preferenciais de avaliação, além da utilização de uma espécie de "escala imaginária" principalmente nos anos finais para emissão de juízos relativos à aprovação ou à reprovação, conforme o atendimento ou não ao perfil disciplinar desejável. Nessas ocasiões, havia uma tendência à aprovação dos alunos localizados nos extremos dessa escala imaginária, e de reprovação daqueles que se alocavam no meio dessa métrica, a partir de uma combinação entre bom comportamento e nivel de aprendizagem que possibilitasse a retomada de um trabalho docente no ano seguinte, uma prática recorrente apoiada em percepções subjetivas, intuitivas dos professores, corroborando a tese de Airasian e Abrams (2003) sobre a diversidade de fontes que alimentam a classificação que o professor faz de seus alunos.

\section{Considerações finais}

0 levantamento realizado nos mostra que a formação docente em avaliação é necessária, considerando o impacto social que as práticas avaliativas têm sobre o percurso escolar e acadêmico dos estudantes. Práticas de avaliação equivocadas, ancoradas em elementos subjetivos, sem o devido respaldo conceitual e técnico, podem produzir efeitos perversos sobre a trajetória escolar de alunos, razão pela qual consideramos urgente que a dimensão da avaliação seja enfatizada na formação docente, tanto inicial quanto continuada, como recomendam Randall e Engelhard (2010) ao defenderem maior atenção dos programas de formação a questões relacionadas a tarefas de avaliação, considerando que muitos educadores, quando se veem diante de uma combinação específica de atributos do aluno, acabam por valorizar esforço e comportamento, diminuindo o significado das notas e provocando conflito entre as partes interessadas.

Se comportamento e empenho fizerem parte da avaliação, é preciso que se crie uma escala para tal, preservando o aluno de julgamentos equivocados que anunciem tratar-se da dimensão cognitiva, quando na verdade enfatizam outras dimensões do desenvolvimento, confirmando a tese de Merle (2018) quanto à irrelevância pedagógica que as práticas avaliativas dos professores adquirem diante de tamanha amplitude de fatores que são considerados para a atribuição de notas. Desse modo, reiteramos a necessidade de

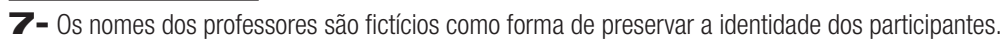


formação docente em avaliação como forma de superar equívocos na ação avaliativa no que se refere a instrumentos, procedimentos, critérios e objetos flutuantes.

Não pretendemos, com este trabalho, deslegitimar a variedade de informações que fomentam a classificação que o professor realiza de seus alunos, mas sim chamar a atenção para o seu uso e, principalmente, para o impacto que isso pode ter quanto à tomada de decisão, especialmente em relação à aprovação ou reprovação escolar, de modo a não permitir que impressões ou convicções em relação aos alunos sejam petrificadas, incidindo em sua trajetória acadêmica, seja na forma como os professores os veem, seja no modo como o próprio aluno se enxerga, capaz ou incapaz, a depender do tipo de relação que é estabelecida com o docente.

\section{Referências}

AFONSO, Almerindo J. Políticas educativas e avaliação educacional. Braga: Universidade do Minho, 1998.

AIRASIAN, Peter W.; ABRAMS, Lisa M. Classroom student evaluation. In: KELLAGHAN, Thomas; STUFFLEBEAM, Daniel L. (ed.). International handbook of educational evaluation. Part two: perspectives. Dordrecht: Kluwer Academic, 2003. p. 533-548.

ALAVARSE, Ocimar M. Desafios da avaliação educacional: ensino e aprendizagem como objetos de avaliação para a igualdade de resultados. Cadernos Cenpec, São Paulo, v. 3, n. 1, p. 135-153, jun. 2013.

ALAVARSE, Ocimar Munhoz; MACHADO, Cristiane; LEME, Luciana França. Avaliações externas e qualidade do ensino: desafios para os conhecimentos dos professores. Trabalho apresentado no Congreso Pedagogía 2013 "Encuentro por la Unidad de los Educadores". Havana, 4 a 8 fev. 2013.

ARELARO, Lisete R. G. Direitos sociais e política educacional: alguns ainda são mais iguais que outros. In: SILVA, Shirley; VIZIM, Marli (org.). Políticas públicas: educação, tecnologias e pessoas com deficiências. Campinas: Mercado de Letras: Associação de Leitura do Brasil, 2003. p. 13-36.

BOWERS, Alex J. Report card grades and educational outcomes. In: GUSKEY, Thomas R.; BROOKHART, Susan M. (ed.). What we know about grading: what works, what doesn't and what's next. Alexandria: ASCD, 2019. p. 32-56.

BRASIL. Constituição da República Federativa do Brasil. Brasília, DF: Senado Federal, 1988.

BRASIL. Estatuto da Criança e do Adolescente. Lei federal n. 8.069, de 13 de julho de 1990. Dispõe sobre o Estatuto da Criança e do Adolescente e dá outras providências. Brasília, DF: Congresso Nacional, 1990.

BRASIL. Lei n. 9.394, de 20 de dezembro de 1996. Estabelece as diretrizes e bases da educação nacional. Diário Oficial da União, Brasília, DF, seção 1, p. 27833, 23 dez. 1996.

BRASIL. Conselho Nacional de Educação. Parecer CNE/CP n. 05/2005, de 13 de dezembro de 2005. Institui Diretrizes Curriculares Nacionais para o Curso de Graduação em Pedagogia. Diário Oficial da União, Brasília, DF, seção 1, n. 92, p. 11-12, 16 maio 2006. 
BRASIL. Ministério da Educação. Portaria 1.570, de 20 de dezembro de 2017. Define a Base Nacional Comum Curricular. Diário Oficial da União, Brasília, DF, seção 1, p. 146, 21 dez. 2017.

BRASIL. Ministério da Educação. Secretaria de Educação Básica. Secretaria de Educação Continuada, Alfabetização, Diversidade e Inclusão. Conselho Nacional da Educação. Diretrizes Curriculares Nacionais Gerais da Educação Básica. Brasília, DF: MEC: SEB: 2013. 542 p.

BROOKHART, Susan M. How to use grading to improve learning. Alexandria: ASCD, 2017.

BR00KHART, Susan M. Teachers' grading: practice and theory. Applied Measurement in Education, v. 7 , n. 4, p. 279-301, 1994.

BROOKHART, Susan M. et al. A century of grading research: meaning and value in the most common educational measure. Review of Educational Research, v. 86, n. 4, p. 803-848, Dec. 2016.

BROWN, Gavin T. L. Conceptions of assessment: understanding what assessment means to teachers and students. New York: Nova, 2008.

BROWN, Gavin T. L. Teachers' conceptions of assessment: implications for policy and professional development. Assessment in Education, v. 11, n. 3, p. 301-308, Nov. 2004.

CASTRO, Maria Helena G. A consolidação da política de avaliação da educação básica no Brasil. Meta: Avaliação, Rio de Janeiro, v. 1, n. 3, p. 271-296, set./dez. 2009.

CASTRO, Maria Helena G. 0 desafio da qualidade. In: ITUASSU, Arthur; ALMEIDA, Rodrigo de (org.). 0 Brasil tem jeito?: educação, saúde, justiça e segurança. v. 2. Rio de Janeiro: Jorge Zahar, 2007. p. 35-72.

CASTRO, Maria Helena G. Sistemas nacionais de avaliação e de informações educacionais. São Paulo em Perspectiva, São Paulo, v. 14, n. 1, p. 121-128, 2000.

CIZEK, Gregory J.; FITZGERALD, Shawn M.; RACHOR, RobertE. Teachers' assessment practices: preparation, isolation, and the kitchen sink. Educational Assessment, v. 3, n. 2, p. 159-179, 1995.

CONFERÊNCIA MUNDIAL DE EDUCAÇÃO PARA TODOS. Declaração Mundial de Educação para Todos: plano de ação para satisfazer as necessidades básicas de aprendizagem. Brasília: Unicef, 1990.

CORTESE, Beatriz P. Vergonha e práticas avaliativas. Estudos em Avaliação Educacional, São Paulo, v. 17, n. 34, p. 95-128, maio/ago. 2006.

CRAHAY, Marcel. Articuler l'évaluation en classe et le pilotage des systèmes, est-ce possible? In: MOTTIER LOPEZ, Lucie (dir.). Évaluations en tension: entre la régulation des apprentissages et le pilotage des systèmes. Bruxelles: De Boeck, 2009. p. 233-251.

CRAHAY, Marcel. Como a escola pode ser mais justa e mais eficaz? Tradução de Fernando Santos. Cadernos Cenpec, São Paulo, v. 3, n. 1, p. 9-40, jun. 2013. 
CRAHAY, Marcel. Podemos lutar contra o insucesso escolar? Tradução de Isabel Almeida Brito. Lisboa: Instituto Piaget, 1996.

CRAHAY, Marcel. Poderá a escola ser justa e eficaz?: da igualdade das oportunidades à igualdade dos conhecimentos. Tradução de Vasco Farinha. Lisboa: Instituto Piaget, 2002.

DALBEN, Ângela. I. L. F. Trabalho escolar e conselho de classe. 4. ed. Campinas: Papirus, 1996.

DÍAZ BARRIGA, Ángel. Uma polêmica em relação ao exame. Tradução de Maria Teresa Esteban. In: ESTEBAN, Maria Teresa (org.). Avaliação: uma prática em busca de novos sentidos. 5. ed. Petrópolis: DP et Alii, 2008. p. 43-66.

DUBET, François. 0 que é uma escola justa?: a escola das oportunidades. Tradução de lone Ribeiro Valle. São Paulo: Cortez, 2008.

ESTEBAN, Maria Teresa. A negação do direito à diferença no cotidiano escolar. Avaliação, Campinas, v. 19, n. 2, p. 463-486, jul. 2014.

FELDMAN, Joe. What traditional classroom grading gets wrong. Education Week, Feb. 3, 2019.

FREIRE, Lílian Rose S. C. Concepções docentes sobre avaliação educacional no contexto de avaliações: um estudo em uma escola da Rede Municipal de Ensino de São Paulo. 2017. Tese (Doutorado em Educação) - Faculdade de Educação, Universidade de São Paulo, São Paulo, 2017.

FREITAS, Luiz Carlos de. Responsabilização, meritocracia e privatização: conseguiremos escapar ao neotecnicismo? Trabalho apresentado no III Seminário de Educação Brasileira, Cedes-Unicamp. Campinas, 28 fev. a 1 mar. 2011.

FREITAS. Pâmela F. Formação docente em avaliação educacional: lacunas, consequências e desafios. 2019. Tese (Doutorado em Educação) - Faculdade de Educação, Universidade de São Paulo, São Paulo, 2019.

GATTI, Bernardete A. Números vazios: entrevista concedida a Rubem Barros. Escola Pública, São Paulo, p. 8-13, set. 2011.

GATTI, Bernardete A. et al. Formação de professores para o ensino fundamental: instituições formadoras e seus currículos. Estudos \& Pesquisas Educacionais, São Paulo, n. 1, p. 95-138, 2010.

HOFFMANN, Jussara. Avaliação: mito e desafio - uma perspectiva construtivista. Porto Alegre: Mediação, 1991.

HOFFMANN, Jussara. Avaliação mediadora: uma prática em construção da pré-escola à universidade. Porto Alegre: Mediação, 1993.

LUCKESI, Cipriano C. Avaliação da aprendizagem escolar: estudos e proposições. 18. ed. São Paulo: Cortez, 2006.

LUCKESI, Cipriano C. Avaliação da aprendizagem escolar: sendas percorridas. 1992. Tese (Doutorado em Filosofia da Educação) - Pontifícia Universidade Católica de São Paulo, São Paulo, 1992. 
MATTOS, Carmem Lúcia G. de. 0 conselho de classe e a construção do fracasso escolar. Educação e Pesquisa, São Paulo, v. 31, n. 2, p. 215-228, maio/ago. 2005.

MERLE, Pierre. Les pratiques d'évaluation scolaire: historique, difficultés, perspective. Paris: Presses Universitaires de France, 2018.

PAJARES, Frank M. Teacher's beliefs and educational research: cleaning up a messy construct. Review of Educational Research, v. 62, n. 3, p. 307-332, 1992.

PATTO, Maria Helena S. A produção do fracasso escolar: histórias de submissão e rebeldia. São Paulo: Casa do Psicólogo, 1990.

RANDALL, Jennifer; ENGELHARD, George. Examining the grading practices of teachers. Teaching and Teacher Education, v. 26, n. 7, p. 1372-1380, 2010.

ROJAS, Hugo de los S. Formação do professor do ensino básico e a avaliação educacional. Estudos em Avaliação Educacional, São Paulo, v. 18, n. 37, p. 7-40, maio/ago. 2007.

SÃO PAULO. Secretaria Municipal de Educação. Diretoria de Orientação Técnica. Portaria n. 5.930, de 14 de outubro de 2013. Regulamenta o Decreto n. 54.452, de 10 de outubro de 2013, que institui, na Secretaria Municipal de Educação, o Programa de Reorganização Curricular e Administrativa, Ampliação e Fortalecimento da Rede Municipal de Ensino de São Paulo - "Mais Educação São Paulo". São Paulo: SME/ D0T, 2013a.

SÃO PAULO. Secretaria Municipal de Educação. Diretoria de Orientação Técnica. Portaria n. 5.941, de 15 de outubro de 2013. Estabelece normas complementares ao Decreto n. 54.454, de 10/10/2013, que dispõe sobre diretrizes para elaboração do Regimento Educacional das Unidades da Rede Municipal de Ensino e dá outras providências. São Paulo: SME/D0T, 2013b.

SÃO PAULO. Secretaria Municipal de Educação. Diretoria de Orientação Técnica. Programa Mais Educação São Paulo: subsídios para a implantação. São Paulo: SME/DOT, 2014a.

SÃO PAULO. Secretaria Municipal de Educação. Diretoria de Orientação Técnica. Programa Mais Educação São Paulo: subsídios 2: Sistema de Gestão Pedagógica - SGP e a avaliação para a Aprendizagem. São Paulo: SME/DOT, 2014b.

SILVA, Marcela M. dos S. et al. A abordagem da avaliação educacional em larga escala nos cursos de graduação em Pedagogia. Revista Brasileira de Estudos Pedagógicos, Brasília, DF, v. 97, n. 245, p. 46-67, jan./abr. 2016.

SIQUEIRA, Valéria A. de S. Avaliações internas e externas: concepções, tensões e articulações no trabalho avaliativo. 2017. Tese (Doutorado em Educação) - Faculdade de Educação, Universidade de São Paulo, São Paulo, 2017.

SOUSA, Clarilza P. (org.). Avaliação do rendimento escolar. Campinas: Papirus, 1991. 
SOUSA, Sandra M. Z. L. Avaliação da aprendizagem: natureza e contribuições da pesquisa no Brasil no período de 1980 a 1990. 1994. Tese (Doutorado em Educação) - Universidade de São Paulo, São Paulo, 1994.

SOUSA, Sandra M. Z. L. Avaliação da aprendizagem na escola de $1^{\circ}$ grau: legislação, teoria e prática. 1986. Dissertação (Mestrado em Educação) - Pontifícia Universidade Católica de São Paulo, São Paulo, 1986.

SOUSA, Sandra M. Z. L.; OLIVEIRA, Romualdo P. de. Sistemas estaduais de avaliação: uso dos resultados, implicações e tendências. Cadernos de Pesquisa, São Paulo, v. 40, n. 141, p. 793-822, set./dez. 2010.

TARDIF, Maurice. A profissionalização do ensino passados trinta anos: dois passos para a frente, três para trás. Tradução Marisa Rossetto. Educação \& Sociedade, Campinas, v. 34, n. 123, p. 551-571, jun. 2013.

THOMPSON, Alba G. Teachers beliefs and conceptions: a synthesis of the research. In: GROUWS, D. A. (ed.). Handbook of research in mathematics teaching and learning. New York: Macmillan, 1992. p. 127-146.

VILLAS BOAS, Benigna M. F.; SOARES, Sílvia Lúcia. 0 lugar da avaliação na formação de professores. Cadernos Cedes, Campinas, v. 36, n. 99, p. 239-254, maio/ago. 2016.

Recebido em: 23.07.2020

Aprovado em: 09.12.2020

Valéria Aparecida de Souza Siqueira é doutora em educação pela Universidade de São Paulo (USP/Capes) e pós-doutora pela USP. Graduada em pedagogia e mestre em educação pelo Centro Universitário Moura Lacerda. É pesquisadora do Grupo de Estudos e Pesquisas em Avaliação Educacional (Gepave).

Pâmela Félix Freitas é doutora em educação pela Universidade de São Paulo (USP), com estágio doutoral na Université de Montréal, sob direção do prof. dr. Maurice Tardif. É pesquisadora do Grupo de Estudos e Pesquisas em Avaliação Educacional (Gepave) e do Centre de Recherche Interuniversitaire sur la Formation et la Profession Enseignante (Crifpe).

Ocimar Munhoz Alavarse é pedagogo pela Universidade Federal de São Carlos (UFSCar). É mestre e doutor em educação pela Universidade de São Paulo (USP). Foi coordenador pedagógico na Rede Municipal de Ensino de São Paulo. É professor na Faculdade de Educação da USP, onde coordena o Grupo de Estudos e Pesquisas em Avaliação Educacional (Gepave). 